\title{
LOS DERECHOS \\ COMO MECANISMOS DE RESISTENCIA AL PODER \\ LA PLURINACIONALIDAD Y LOS DERECHOS INDÍGENAS \\ DESDE EL MOVIMIENTO INDÍGENA ECUATORIANO'.
}

\author{
JOHANNA ROMERO LARCO ${ }^{2}$
}

\section{RESUMEN}

A partir de la relación de los elementos estructura del Estado y derechos sociales, proponemos un análisis distinto al tradicional, que entiende en un sentido unidireccional, que los derechos sociales están determinados por la estructura de poder. Nuestra propuesta plantea la posibilidad de que los derechos pueden no ser capturados por el poder estatal, sino, a través de ellos mismos, poner en crisis la propia estructura del Estado.

La propuesta de este trabajo es evaluar, a partir del caso ecuatoriano, si la incorporación de derechos económicos, sociales y culturales de los derechos de pueblos y nacionalidades indígenas, es posible encontrar alguna vía de restructuración del Estado y una ruptura al modelo clásico de concentración del poder. A través de las tesis del Estado Plurinacional, es que queremos sugerir una lectura más amplia de los derechos como herramientas que permitan no solo limitar al poder, sino desconcentrarlo.

1 Artículo entregado por el autor el 30 de mayo de 2017 y aprobado el 15 de junio de 2017.

2 Abogada por la Universidad de Cuenca, Máster en Derecho Constitucional por la Universidad Andina Simón Bolívar, candidata a Doctora en Derecho por la Universidad de Buenos Aires (UBA). 


\section{PALABRAS CLAVE}

Estado Plurinacional, Plurinacionalidad, derechos económicos, sociales y culturales, estructura del Estado, movimiento indígena.

\section{ABSTRACT}

Based on the relationship between the elements State structure and social rights, we propose a different analysis from the traditional one that understands in an unidirectional way that social rights are determined by the power structure. Our proposal raises the possibility that rights may not be captured by State power, but through themselves, putting into crisis the very structure of it.

The proposal of this paper is to evaluate, from the Ecuadorian perspective, whether the incorporation of economic, social, and cultural rights of the rights of indigenous peoples and nationalities is possible to find some way of restructuring the State, and produce a rupture to the classic model of concentration of power. Through the thesis of the Plurinational State, we want to suggest a broader reading of rights as tools that allow not only to limit power, but also to defuse it

\section{KEY WORDS}

Plurinational State, plurinationality, economic, social, and cultural rights, structure of the State, and indigenous movement 


\section{INTRODUCCIÓN}

En un trabajo reciente que revisa los dos siglos de Constitucionalismo en América Latina ${ }^{3}$ (1810-2010), Roberto GARGARELLA afirma que todo proceso de reforma legal que ha acontecido durante este período ha supuesto una convivencia -aunque sea transitoria- del Derecho vigente con aquel que se incorpora. Tal convivencia, agrega GARGARELLA, no es pacífica, y menos aún supone una adaptación temporal y progresiva de uno y otro derecho, sino que siempre se produce en una continua tensión e imposición de uno sobre otro. ${ }^{4}$

En materia constitucional, y de manera más específica en el ámbito de las reformas constitucionales, la tesis de GARGARELLA sostiene que en el contexto latinoamericano, la relación derecho vigente-reforma es asimismo conflictiva, pero además, el Derecho vigente, que resulta del pacto conservador-liberal, va a terminar por imponerse ante cualquier reforma o injerto que suponga alguna tensión o disminución de poder de ese primer pacto.

Característica de ese modelo de constitucionalismo conservador, según Gargarella, es la concentración del poder en el Ejecutivo, una forma de presidencialismo atenuado que, en tanto confiere cada vez más poderes al Ejecutivo, desplaza progresivamente al poder Legislativo. ${ }^{5}$

3 GARGARELlA, Roberto. La sala de máquinas de la Constitución. Dos siglos de constitucionalismo en América Latina (1810-2010). Buenos Aires: Katz, 2015.

4

GARGARELLA, R., op. cit., p. 243.

5 GARGARELLA, R., op. cit., pp. 49-89. 
En un análisis que vincula los contenidos constitucionales y el contexto socio-político que se desarrolló en América Latina desde mediados del siglo XX, el autor pone de manifiesto la progresiva incorporación de los derechos sociales en el ámbito del constitucionalismo latinoamericano, a lo que cataloga como una forma de constitucionalismo de corte más radical, en el sentido de más democrático. No obstante ello, en un contexto en donde el Derecho vigente es de tinte conservador, pero además renuente a las demandas sociales, el resultado es que esos derechos sean leídos en clave conservadora ${ }^{6}$.

Las razones que explicarían esa lectura sesgada de los derechos, están -según GARGARELLA- en la tensión que se da entre los derechos económicos, sociales y culturales, por un lado, y el poder, por el otro, que en Latinoamérica se traduce en presidencialismo. En consecuencia, el presidencialismo se impone a los derechos, en la medida que estos últimos se constituyen en una limitación al poder, por lo que el Ejecutivo tiende a contenerlos, dando como resultado el deterioro en los derechos económicos, sociales y culturales.

Visto así, este posible fracaso de los derechos sociales en el Constitucionalismo Latinoamericano responde a que si bien existe un pliego de derechos, que ha ido incrementándose progresivamente en las Constituciones de los Estados latinoamericanos, la estructura del poder se mantiene intacta. Lo que GARGARELla denomina como "Sala de Máquinas de la Constitución", en donde se configura la estructura del Estado, no sigue la misma dinámica progresista de la parte dogmática, sino una vía totalmente contraria; la concentración. Así, aunque

6

GARGARELLA, R., p. 246. 
se amplíen los derechos, y la "Sala de Máquinas" siga intacta, no hay posibilidad de éxito de los primeros, su lectura seguirá siendo fiel al pacto liberal-conservador y difícilmente podrá significar un límite al poder.

En este orden de ideas, GARGARELLA afirma que en gran medida el presidencialismo, que es característico de Latinoamérica, se constituye en uno de los factores que explican no sólo las graves crisis institucionales en la región, sino principalmente las graves afectaciones a los derechos sociales. De suerte que, aún en un contexto en donde el catálogo de derechos ha tendido a incrementarse, las amplias facultades del Poder Ejecutivo son factor de trasgresión a esos derechos ${ }^{7}$. La tensión entonces se da entre derechos sociales y presidencialismo.

\section{La propuesta metodológica}

A partir de la lectura anterior, es posible encontrar en las reformas constitucionales más recientes de la región, tales como Venezuela (1999), Ecuador (2008) y Bolivia (2009), un claro ejemplo de lo que GARGARELLA menciona como una desatención en la "Sala de Máquinas", y una excesiva preocupación por la declaración de derechos, cuando, según menciona, la salida estaría en dar igual o mayor atención a la estructura del Estado por sobre los derechos sociales, si lo que pretendemos es que estos últimos triunfen.

Se trata entonces de una tesis que mira a los derechos como sometidos o dependientes de la organización del poder, y no sólo en una simple interconexión entre la parte orgánica y dogmática,

7

GARGARELLA, R., op. cit., pp. 269-208. 
de forma que el triunfo o fracaso de los derechos depende de qué tanto se mueve la "Sala de Máquinas." Se trata de una lectura que sostiene una sola vía de incidencia, el poder sobre los derechos, pero además circunscripta en la norma y en el Estado. En esta lectura no hay, o no es relevante para el autor, una incidencia en la dirección contraria, los derechos no podrían modificar la estructura del Estado con la misma intensidad que sobre ellos se genera, ni hay una posibilidad de tensión por fuera del Derecho, en una instancia no estatal. Es aquí donde consideramos que es posible plantear otro análisis, una posibilidad de mirar en los derechos como potenciales factores de resistencia al poder estatal y no estatal.

Utilizando la misma relación que propone el autor, estructura del Estado-derechos sociales, proponemos un análisis distinto de tal relación, en la que se evalúe si, contrario a lo que opina GARGARELLA, los derechos pueden no ser capturados por el poder estatal, sino a través de ellos mismos poner en crisis la propia estructura del Estado.

La propuesta de este trabajoes evaluar, a partirdelcasoecuatoriano, si la incorporación de derechos económicos, sociales y culturales de los derechos de pueblos y nacionalidades indígenas pueden significar en alguna manera una reestructuración del Estado y una ruptura al modelo clásico de concentración del poder. A través de las tesis del Estado Plurinacional, es que queremos sugerir una lectura más amplia de los derechos como herramientas que permiten no solo limitar al poder, sino desconcentrarlo.

Si llevásemos la lectura de la "Sala de Máquinas" para el caso particular del movimiento indígena ecuatoriano, y las demandas que éstos han planteado desde el siglo anterior, uno podría 
concluir que el movimiento indígena incurrió en el error de concentrar su atención en las declaraciones de derechos de tal sector social, descuidando la "Sala de Máquinas". Es decir, que el posible fracaso de las luchas por los derechos de los pueblos y nacionalidades indígenas, como pareciera inferirse del trabajo del autor, responde a que sus demandas no incorporan una modificación en la estructura del poder, aunque pudieron haberlo hecho, pues la plurinacionalidad supone la posibilidad de que la "nación" indígena reclame sus propias instituciones.

$\mathrm{Si}$ bien las demandas indígenas, principalmente las que se instalan en Ecuador desde fines de los años ochenta e inicios de los noventa, incluyen derechos de propiedad, salud, educación, etc., la consigna principal detrás de ellas es el reconocimiento por parte del Estado de la Plurinacionalidad, de una sociedad diversa, en donde conviven concepciones de vida diversas, heterogéneas, de manera que las demandas indígenas no suponen la simple declaración de derechos, sino que parten de una exigencia previa y externa por el reconocimiento del Estado como Plurinacional que, como se pretende analizar, significa un profundo cuestionamiento a la estructura conservadora del Estado. Aún más, esta demanda incluye un reconocimiento anterior del indio, de lo indígena en la sociedad, no como una individualidad aislada en la sociedad, sino como un sector predominante, influyente y característico del país.

Se propone, entonces, una comprensión del poder por fuera de la norma y el Estado, en tanto consideramos que abordarlo solamente desde esa faceta, desconoce todas las tensiones previas que cualquier conquista de derecho incluye. La idea es indagar el proceso político de positivización de los derechos de los pueblos indígenas, la lucha y el conflicto que le antecede a la incorporación 
de derechos en las Constituciones. Así, contrario a la lectura de GARGARELLA sobre las reformas y procesos constituyentes, lo que se pretende evidenciar es que la incorporación de determinados derechos en las Cartas Políticas, son en sí mismas el resultado de una lucha de poder que el Estado no ha podido resistir, en donde las movilizaciones que ha dado el movimiento indígena han sido verdaderos mecanismos de resistencia al poder en su intento por ser invisibilizados y excluidos.

De lo que se trata es de pensar que en esa construcción de un saber, en este caso los derechos, hay un camino que va desde su formulación epistémica hasta su instrumentalización técnica, que está atravesada por las complejidades de un contexto histórico y político específico, que hacen evidente las relaciones de poder, dentro de luchas políticas que utilizan distintas formas de dominio, legitimación y justificación teórica.

Ahora bien, esta concepción pareciera no alcanzar para negar el planteamiento principal de GARGARELLA respecto de una "Sala de Máquinas", que se fortalece por un presidencialismo que tiende cada vez más a la trasgresión de los derechos. Sin indagar muy a fondo, pues no es objetivo de este trabajo, se puede plantear la siguiente interrogante. ¿Existe en realidad la relación directa entre presidencialismo y la trasgresión de derechos? El caso del Peronismo en Argentina en los años cuarenta, el propio chavismo en los noventa, los períodos iniciales de gobierno de Rafael Correa en Ecuador y Evo Morales en Bolivia podrían contradecir esa premisa. Perón, Chávez, Correa y Morales han sido gobiernos sostenidos sobre sistemas presidencialistas muy marcados, y sin embargo, el avance efectivo en materia de derechos sociales no puede ser desmentido. Al parecer, la relación presidencialismoderechos sociales no es directa como lo muestra GARGARELLA, es 
muy probable que exista una variable intermedia que condicione tal relación. Nos aventuramos a pensar que esta variable intermedia no necesariamente es Estatal, ni jurídica, sino externa y económica.

Finalmente, junto al ámbito normativo (Constituciones) y socio-político antes esbozado, introducimos una última línea de análisis que tiene que ver con lo que consideramos un posible mecanismo de negación de lo indígena como herramienta de reacción a la crisis que la Plurinacionalidad plantea. A través de la revisión de los Censos Poblacionales, las variables usadas, las metodologías y cifras expuestas, se pretende mostrar que el Estado, en su intento por anular o negar la presencia masificadora de la organización indígena en el país, recurrió al control de esta población, mediante un mecanismo que validaba lo indígena desde su propia concepción, es decir, desde criterios determinados por el Estado.

En suma, se propone un análisis que intenta un estudio de la relación derechos-población-movilización, para evaluar si los actuales contenidos dogmáticos en las Constituciones pueden ser entendidos también como vías de tensión al poder, que no soportan su anulación. De manera que, sin considerar que la apuesta a las declaraciones de derechos es excesiva frente a la "Sala de Máquinas", se pueden constituir también en espacios de poder. 


\section{Multiculturalidad y Plurinacionalidad antes de Montecristi}

Para abordar la noción de Plurinacionalidad, tomaremos como referencia los aportes de Salvador SCHAVELZON, no solo por la actualidad y contexto de análisis, sino por el trabajo etnográfico desde el cual se aborda, lo cual ha llevado a Eduardo GUDYNAS a mencionar en el Prólogo de la obra que el trabajo de SCHAVELZON, constituye una suerte de "microhistoria de conceptos claves".

En una interesante propuesta por indagar los conceptos de Plurinacionalidad y Buen Vivir en los recientes procesos constituyentes de Ecuador y Bolivia, Salvador SCHAVELzon propone una indagación por la irrupción de mundos indígenas en la política moderna del sistema político ecuatoriano y boliviano; por encontrar en estos, ya no solo una fuerza de resistencia o choque entre mundos, sino el producto de la reorganización política indígena “...de la dinámica colonial y estatal que incorpora lo externo y de la crisis institucional, ambiental y política de la democracia capitalista occidental" 9 .

Para SCHAVELZON, el concepto de Plurinacionalidad, al igual que el de Buen Vivir, debe ser considerado como una combinación compleja de distintas miradas y experiencias políticas ${ }^{10}$; de allí como lo menciona GUDYNAS, este trabajo no postula ideas rígidas “.... sino que advierte sobre proposiciones no siempre precisas, muchas veces difusas, con superposiciones y contradicciones..."11.

GUDYNAS, Eduardo. Prólogo, en SCHAVELZON, op cit., p. 11.

9 SCHAVELZON, Salvador. Plurinacionalidad y Vivir Bien/Buen Vivir. Dos conceptos leídos desde Bolivia y Ecuador post-constituyentes. Quito: Abya Yala, Clacso, p. 16

SCHAVELZON, S., op., cit.

11 GUDYNAS, E., op cit. 
En lo que nos interesa resaltar aquí, SCHAVELZON señala que la plurinacionalidad inspira toda una discusión sobre las formas políticas, en la cual se "[c]uestiona el aparente consenso sobre la república y la representación individual moderna, tan articulada como está con el Estado de derecho, la protección de la propiedad privada y tantos sentidos que son una continuación de la Colonia"12.

En la década de los noventa, en el Ecuador, el movimiento indígena consigue introducir al debate político las demandas de derechos colectivos, territorialidad, plurinacionalidad, interculturalidad, justicia indígenas, los mismos que suponían un primer replanteamiento a la noción de Estado, de Nación, ciudadanía, autonomía y autodeterminación construidas en el contexto del liberalismo, occidental y moderno. Es así que, a través de la idea de plurinacionalidad, se lleva a cabo un cuestionamiento del modelo de Estado neoliberal, y se plantea la reconfiguración de un nuevo Estado, en el que la diferencia y la diversidad histórica y cultural se tornen como un factor relevante.

La Plurinacionalidad pone en crisis los fundamentos del Estadonación, al introducir la cultura como categoría relevante que contribuya a la constitución de una sociedad más igualitaria en contextos de diferencia, y no a la exclusión como tradicionalmente fue utilizada. A través de la demanda por el Estado Plurinacional, el movimiento indígena coloca sobre la mesa la necesidad de promover diálogos interculturales, con lo cual el desafío implicaba abandonar la idea de una cultura universal, con valores y principios igualmente universales, en tanto existe un "otro" distinto, con igual derecho para vivir ${ }^{13}$.

12 SCHAVELZON, S., op cit, p. 17.

13 DÁVALOS, Pablo. "El movimiento indígena ecuatoriano: la constitución de un 
A este punto, la plurinacionalidad se posicionaba no solo como una demanda política, sino también como una construcción teórica que tiene la particularidad de no ser configurada como un proyecto indígena, sino como un proyecto social y político, con dimensiones de-coloniales para toda la población y que no se traduce en una superposición de culturas, sino de unidad en la diferencia.

Aunque en términos jurídicos la demanda del Estado Plurinacional empezó a insertarse desde la Constituyente de 1998, fueron las críticas de parte de las élites políticas conservadoras quienes, alegando un supuesto intento separatista de parte del movimiento indígena, hacían que esta demanda pierda adherentes y como consecuencia de aquello, el texto constitucional de entonces se limite a reconocer la interculturalidad. Según Mónica Chuji, el proyecto de plurinacionalidad empezó en 1998 con el reconocimiento de la intercurlturalidad, pero el abandono del carácter nacional, homogéneo y monocultural del Estado, debía ser superado en dirección a la construcción del Estado Plurinacional ecuatoriano ${ }^{14}$.

Así, aunque la Constituyente de 1998 no significara un triunfo, el movimiento indígena logró abrir un diálogo intercultural con la sociedad, a la vez que posicionó nuevos temas en la agenda política, y en lo que nos interesa aquí resaltar, visibilizó a los indios como un nuevo actor social. Señala Pablo DÁvalos; "No se trataba solamente de afirmar la identidad propia frente a un sistema en permanente tarea de destrucción de los diferente, se trataba también de sumar voluntades, de lograr que sea la

actor político", en http://icci.nativeweb.org/papers/davalos1.pdf. Internet (Visita 4-4-16). 
sociedad en su conjunto la que reconozca la interculturalidad y la plurinacionalidad"15.

\section{Constituciones, censos y movilización social}

En esta sección, se intentará cruzar tres elementos de análisis. Por un lado, las Constituciones de 1979, 1998 y 2008, procurando identificar en éstas las demandas indígenas incorporadas; por otro, los censos de 1950, 1990, 2001 y 2010, haciendo hincapié en las cifras obtenidas y las variables de identificación. Todo esto contrarrestado con un elemento socio-político que implica el desarrollo del movimiento indígena, es decir, cómo éste se ha venido organizando, cuáles han sido sus principales demandas y cuáles fueron las medidas adoptadas en determinados contextos.

Bajo estos tres elementos, Constitución, Censos y movilización, se propone evaluar cómo la incorporación en las Constituciones de nuevos derechos no son simples declaraciones insertas en el ámbito netamente jurídico, sino que son el resultado de constantes luchas entre el poder político, estatal y no estatal y el movimiento indígena, que por fuera del Derecho disputan, el reconocimiento étnico por el lado de los indígenas y la unidad del Estado por el lado del poder estatal.

La década de los noventa se constituye en la etapa de mayor movilización e influencia del movimiento indígena en Latinoamérica, que hace frente a la llegada del neoliberalismo en la región. El Ecuador, en ese contexto, se constituye en el epicentro del primer levantamiento indígena del continente del siglo XX, con el Paro Nacional Indígena de junio de 1990 y que generará réplicas en varios otros países ${ }^{16}$.

15 DÁVALOS, P., internet.

16 En 1994 aparecerá el EZNL en México, y en 1999 la Revolución del Agua en Bolivia. 
Si bien la década de los noventa es el momento de mayor presencia y movilización indígena, su mención aquí merece también prestar atención a la etapa que precedió al Paro Nacional, con el propósito de encontrar en ella algunos elementos para entender lo que sucedería con posterioridad en los tres espacios que analizamos (Constitución-población-movilización).

En 1979, después de casi ocho años de gobiernos militares, las élites políticas veían la necesidad de construir un escenario propicio para estructurar una nueva institucionalidad social, política, económica y jurídica en el país. Osvaldo Hurtado, vicepresidente y entonces encargado del Estatuto del Referéndum de 1978, lo mencionaba así: "Era necesario crear instituciones políticas que respondieran a las nuevas realidades nacionales generadas por los cambios económicos y sociales originados en la aparición del petróleo" ${ }^{17}$. Las palabras de Hurtado reflejan, sin duda, la dirección que la Constitución de 1979 pretendía tomar; modernizar el Estado.

En lo que interesa mencionar aquí, la Constitución de 1979 significó, en el ámbito jurídico, un punto de partida. Se reconoció el quichua y demás lenguas aborígenes como "parte de la cultura nacional", ${ }^{18}$ el voto voluntario de analfabetos (Art. 3319) que

HURTADO, Osvaldo. Política Democrática: los últimos veinte y cinco años. Quito: FESO, Corporación Editora Nacional, 1990.

Art. 1.- El Ecuador es un Estado soberano independiente, democrático y unitario. Su gobierno es republicano, electivo, responsable y alternativo. La soberanía radica en el pueblo que la ejerce por los órganos del poder público. El idioma oficial es el castellano. Se reconocen el quichua y demás lenguas aborígenes como integrantes de la cultura nacional..."

Constitución de Ecuador 1979, Decreto Supremo 000, Registro Oficial N. ${ }^{\circ}$ 800, de 27 de marzo de 1979. Art. 33.- El voto es universal, igual, directo y secreto, obligatorio para los que sepan leer y escribir y facultativo para los analfabetos. Tienen derecho a voto los ciudadanos ecuatorianos que hubieren 
junto a la adopción del sistema unicameral (Art. 56) ${ }^{20}$ abrían la posibilidad de la participación política de nuevos actores políticos. No obstante este mismo proceso constituyente, introducía como parte de la idea modernizadora, la declaración del Estado como "independiente, democrático y unitario", y la exigencia de un título académico para ser elegido ${ }^{21}$. Así, aunque la cuestión indígena empieza a ocupar un espacio en el ámbito jurídico, se ve, a la par, limitado por otras reformas de contenido liberal. Hay una primera identificación del indígena, pero que se limita a mirarlo como sujeto de derechos políticos.

De todas formas, tomamos a la Constitución de 1979 como el antecedente más remoto en el Constitucionalismo ecuatoriano, que introduce en el saber jurídico una demanda indígena; la lingüística. Este hecho, sin embargo, no es aislado. Proponemos

cumplido dieciocho años de edad y se hallen en goce de los derechas políticos. Los miembros de la Fuerza Pública en servicio activo no hacen uso de este derecho.

El reconocimiento del voto facultativo, significó el incremento notable de participación de los indígenas en los procesos electorales a nivel local y nacional.

Art. 56.- La Función Legislativa es ejercida por la Cámara Nacional de Representantes, con sede en Quito e integrada por doce representantes elegidos por votación nacional; dos representantes elegidos por cada provincia, a excepción de las de menos de cien mil habitantes, que eligen uno; y, además, por un representante elegido por cada trescientos mil habitantes o fracción que pase de doscientos mil. Los representantes son elegidos de entre los candidatos presentados por los, partidos políticos reconocidos legalmente, en listas que son calificadas por la función electoral, de acuerdo con la ley. La base de elección de trescientos mil o fracción de doscientos mil, se aumenta, en la misma proporción en que se incremente la población nacional, de acuerdo con los censos. Excepcionalmente, la Cámara Nacional de Representantes se reunirá en cualquier otra ciudad.

21 Con la reforma constitucional de 1983, este requisito será eliminado. Esta Constitución fue reformada doce veces entre 1979 y 1998. 
dos sucesos anteriores que consideramos repercuten, en algún sentido, en este ámbito.

Desde una perspectiva socio-política se puede observar que, previamente a la Constituyente de 1979, el movimiento indígena ecuatoriano se encuentra en pleno proceso de estructuración. Es la etapa en que se pasa de las demandas estrictamente clasistas a una más específica, la étnica. Es la fase que inicia la transición de la FENOC, Federación Nacional de Organizaciones Campesinas, a la CONAIE, Consejo de Nacionalidades Indígenas del Ecuador. Surgen; por entonces, movimientos indígenas y clasistas que se agrupan y concentran sus demandas en las condiciones económicas de los trabajadores de la tierra, con lo cual lo étnico ocupa un rol secundario; de allí que la Reforma Agraria, por ejemplo, no haya logrado erradicar la situación de pobreza, explotación y exclusión que mantenía a la población indígena en los huasipungos.

Es la etapa en la que, aunque se incorporan importantes reformas en materia laboral, que luego serán incluidas en la Constitución de 1978, la demanda étnica no es aún considerada relevante, por lo que la organización indígena que emergía toma el derecho a la tierra como la bandera de lucha en contra de los grandes hacendados respaldados por el Estado.

Es sólo en 1972, con la aparición en la Sierra, de la Confederación de Pueblos de las naciones Quechua del Ecuador (ECUARUNARI) y en la Amazonía de la Confederación de Nacionalidades Indígenas de la Amazonía Ecuatoriana (CONFENAIE) que la bandera étnica es finalmente incorporada al movimiento indígena. Para inicios de los ochenta, ambas agrupaciones integrarán el Consejo de Coordinación de las Nacionalidades Indígenas del Ecuador 
(CONACNE), que luego se convertiría en la Confederación de Nacionalidades Indígenas del Ecuador (CONAIE).

La CONAIE, que empezó por sostener como línea de lucha la recuperación de la tierra y de los territorios confiscados, posteriormente, tras el distanciamiento con las organizaciones de izquierda, ${ }^{22}$ se planteó pensarse desde su filosofía ancestral y desde allí proponer la construcción de un Estado que permita la redefinición de las relaciones sociales. Es entonces que se incorporan demandas como la reafirmación de las culturas y la unidad en la diversidad, la construcción de un poder alternativo propio, la reconstrucción de las nacionalidades y pueblos como entidades históricas y políticas, y, en lo que aquí interesa destacar, la construcción de un Estado plurinacional alternativo al Estado liberal, uninacional, incluyente e intercultural, que supere toda forma de opresión y explotación ${ }^{23}$.

Por lo tanto, para los ochenta la línea étnica-cultural termina por articular las movilizaciones indígenas y generar un motor de fuerza para la organización, sin dejar de hacer énfasis en la condición de pobreza a la que se veían sometidos como rezago colonial en pleno ciclo liberal.

A este proceso socio-político de estructuración del movimiento indígena contraponemos otro, que, según creemos, tiene que

22 Este énfasis en lo étnico, como categoría distinta a la de clase, significó para el movimiento indígena, el distanciamiento con la izquierda, que hasta entonces incorporaban las demandas indígenas a una situación de clase.

Maldonado, Luis ."Movimiento indígena y participación política en Ecuador", en Incidencia de la participación política de los pueblos indígenas: un intercambio de experiencia de Bolivia, Ecuador y Guatemala. Guatemala: Fundación Konrad Adenauer, 2006, p. 31. 
ver con el mecanismo por el cual el indígena empieza a ser reconocido por el Estado, no como un sujeto de derechos, sino como parte de la población, es decir, como un individuo en la sociedad. Lo que se intenta sostener aquí es que a partir del levantamiento estadístico vía los censos poblacionales, el Estado no sólo que ve la necesidad de identificar al indígena, sino también de diferenciarlo, pero según sus propios criterios, no sólo como mecanismo de control de esa población, sino también de estigmatización.

Lo que se quiere mostrar es que ese fuerte proceso de configuración socio-política del movimiento indígena, que luego tendrá una primera muestra en el ámbito jurídico con la Constitución de 1978, tiene un paso intermedio en el reconocimiento mismo del indígena como parte de la población. No obstante, ese reconocimiento es apropiado por el Estado, de suerte que es éste quien determina quién y cómo se es indígena.

Aunque son varios los estudios que se han llevado a cabo sobre población indígena en el Ecuador, ha sido nota característica encontrar entre ellos grandes diferencias entre las cifras estatales y no estatales ${ }^{24}$. Lo que aquí interesa observar es cómo ha identificado el Estado a la población indígena, por lo que tanto no interesan las cifras que no provengan desde alguna instancia estatal, por lo que se recurre como fuente principal a los datos que provee el Instituto Nacional de Estadísticas y Censos (INEC) a través de los censos de población.

24 Estudios como los de Gregory KNAPP en 1987, considerado por la CEPAL el más completo, es un ejemplo de esto. KNAPP, Gregory. Geografía Quichua de la Sierra del Ecuador. Núcleos, dominios y esfera, Quito, Abya-Yala, 1987. 
Lo que nos interesa es mirar a los censos poblacionales como un mecanismo o tecnología en la creación de identidades, en este caso la indígena, para clasificar, ordenar y administrar a esta población ${ }^{25}$. No es, por tanto, extraño que la CEPAL haya mencionado en un diagnóstico sobre población, que solo a partir del Primer Censo Poblacional de 1950 se tiene una visión aproximada sobre la población indígena en el Ecuador ${ }^{26}$.

Desde el primer censo poblacional de noviembre de 1950 hasta la actualidad, se han llevado a cabo siete procesos censales, ${ }^{27}$ de los cuales solo cuatro de ellos (1950, 1990, 2001 y 2010) incorporaron, en distinta forma, alguna variable que permite identificar a la población indígena del país.

En el I Censo Poblacional de 1950, a través de la variable "idioma" se obtuvo una primera cifra del número de indígenas

FOUCAUlT, Michael. Seguridad, Territorio y Población, Trad. de Horacio Pons, Buenos Aires: Fondo de Cultura Económica, 2006, p. 139.

26 CEPAL, "Población indígena y afroecuatoriana en Ecuador: Diagnóstico sociodemográfico a partir del censo de 2001". Santiago de Chile, 2005, p. 16. Internet.

Aunque durante la colonia se efectuaron algunos censos, estos solo tenían un fin de recaudación tributaria. En 1780 el Primer Censo Colonial utilizando un criterio fenotípico que distinguía entre "blancos", "indios", "libres de varios colores" y "esclavos", identificó que el 64\% de la población nacional era indígena; de las 412.000 personas que integran la población tributaria, 265.000 eran indios. En el Censo republicano de 1850 se calculó una población total de 604.000, de los cuales, bajo el mismo criterio fenotípico, se registró a 280.000 indígenas, es decir el 46\% de población nacionalhttp:/ / repositorio.cepal.org/ bitstream/handle/11362/4140/S2005013_es.pdf?sequence=1

1950, el I Censo de Población; en 1962, el II Censo de Población y I de Vivienda; en 1974, el III Censo de Población y II de Vivienda; en 1982, el IV Censo de Población y III de Vivienda; en 1990, el V Censo de población y IV de Vivienda; en 2001, el VI Censo de Población Y V de Vivienda y en 2010, el VII Censo de Población y VI de Vivienda 2010. 
que habitaban el territorio ecuatoriano. Esta cifra, que no hacía totalmente visible a la población indígena, no tenía como propósito el relevar datos étnicos, sino distinguir a la población monolingüe y bilingüe que habitaba el territorio. De suerte que es solo como consecuencia de esta variable, que fue posible extraer un primer dato ${ }^{28}$.

Un dato que llama la atención en el documento del Ministerio de Economía que recoge los datos del censo es que para establecer los descriptores del carácter indígena de la población se vincularon en la tabulación de datos las variables idioma, alfabetismo, uso de cama y calzado y tipo vivienda (Tablas N. 28 en adelante). De suerte que, como lo menciona Mercedes PRIETO, persistía en el imaginario común una asociación de lo indígena con un primitivismo, de donde la choza, la ausencia de cama y calzado eran "atributos" eminentemente indígenas 29 .

Según este criterio lingüístico, el número de habitantes que hablaban un "idioma o dialecto aborigen" es de 343.745 personas. Esta cifra incluye monolingües (de quechua, cayapa, jíbaro y

28 En el Resumen de Características del Ministerio de Economía, llama la atención que, según lo indica el documento "Para la clasificación se ha tomado en cuenta el idioma que hablaba cada persona con los miembros de su familia en combinación con otro idioma o dialecto que mejor hablaba el empadronado." En Primer Censo de Población del Ecuador, 1950, Resumen de Características, Volumen único, Ministerio de Economía, Quito, 1960, (Tablas 12,13 y 14).

29 Ver Primer Censo de Población del Ecuador, 1950, Resumen de Características, Volumen único, Ministerio de Economía, Quito, 1960, p. 136 ss. Y Mercedes Prieto, El estado ecuatoriano a mediados del siglo XX: el censo, la población y la familia indígena, Revista Europea de Estudios Latinoamericanos y del Caribe, ERLACS, No 99, Octubre, 2015, pp. 29-46. Internet http:/ / www.erlacs.org/ articles/abstract/10.18352/erlacs.10104/ (Visita 15/4/16). 
záparo) y bilingües (castellano + idioma o dialecto aborigen, e; idioma o dialecto aborigen + castellano) de un total de 3`202.757 habitantes ${ }^{30}$, es decir, el $10,7 \%$ de la población ecuatoriana fue considerada en 1950 como indígena ${ }^{31}$.

Luego del censo de 1950, se llevaron a cabo tres más, pero ninguno de ellos incorporó una variable que permitiera identificar a la población indígena, sino hasta 1990, con lo cual es posible pensar que la gesta movilizadora de los indígenas requería ser invisibilizada, y un mecanismo pudo ser éste.

En noviembre de 1990, cuarenta años después del primer censo, se realizó el V Censo Poblacional y IV de Vivienda, éste retomará el criterio lingüístico para identificar a la población indígena. La boleta censal de entonces incluyó la pregunta: “¿Qué idioma hablan entre sí los miembros del hogar?" en donde las opciones incluían: lengua nativa, español y lengua extranjera ${ }^{32}$. De suerte que a partir de una variable -nuevamente- lingüística, el Estado reconocía como indígena a quienes se comunicaban en alguna

Hay que recordar que la población que es tomada en cuenta para extraer datos por la variable "lengua o dialecto", es a partir de los seis años de edad. De allí que, el porcentaje sea en relación nacional registrada y no al número de censados para esta variable.

Según Chisaguano, la boleta censal introdujo la variable "lengua hablada" de donde se extrajo que de quienes hablaban una lengua distinta al castellano, el 97,5\% habla quechua, y el 2,3\% jíbaro. En, Silverio Chisaguano, La Población Indígena del Ecuador. Análisis e Estadísticas socio-demográficas, INEC, Quito, 2006. Internet: http://www.acnur.org/t3/fileadmin/ Documentos/Publicaciones/2009/7015.pdf?view=1 (visitado el 28/3/16).

INEC, Evolución de las variables investigadas en los censos de población y vivienda del Ecuador. 1950, 1962, 19974, 1982, 1990, 2001 y 2010, Anexo. Internet http://www.ecuadorencifras.gob.ec/documentos/web-inec/

Publicaciones/Evolucion_variables_1950_2010_24_04_2014.pdf(Visita 29-32016). 
lengua indígena en el seno familiar ${ }^{33}$. Un total de 363.500 personas respondieron que sí, es decir, el 3,8\% de la población nacional que para aquel año era de 9`648.189 habitantes, se reconocía -a partir del censo- como indígena.

Llama la atención el cambio que entre 1950 y 1990 se da en las estadísticas poblacionales respecto de la población indígena. El paso de un $10.7 \%$ a un $3,8 \%$ sugiere detenerse para identificar algunos hechos que acontecieron previamente al censo de 1990.

El 28 de mayo de 1990, es decir, siete meses antes del V Censo Poblacional, cientos de indígenas y campesinos se tomaron en Quito, durante diez días la Iglesia de Santo Domingo. La medida se anticipaba y anunciaba un levantamiento indígena nacional para los días 4, 5 y 6 de junio de 1990 y con ella la proclama denominada "Mandato por la defensa de la vida y los derechos de las nacionalidades indígenas"; ésta incluyó las siguientes propuestas y demandas:

1. Entrega y legalización de tierras.

2. Solución de los problemas de agua para regadío, consumo y políticas de no contaminación.

3. No pago del predio rústico.

4. Cumplir y hacer cumplir el acuerdo de Sarayacu ${ }^{34}$.

33 La metodología utilizada por el INEC a través de esta pregunta, fue criticada por la dirigencia indígena, pues no reflejaba con claridad la realidad de ese sector. Según SÁNCHEZ-PARGA, la pregunta no permitió una respuesta múltiple, lo que daba lugar a subestimaciones dado que la población bilingüe quichua-castellano y castellano-quichua podía ser considerada indígena. SÁNCHEZ-PARGA, José. Población y pobreza indígenas. Quito: CAAP, 1996, p. 18.

34 El Acuerdo de Sarayacu consistía en el acuerdo dado en mayo de 1989 y que implicaba el compromiso del gobierno en entregar los títulos de propiedad a las comunidades indígena, obtenida por reivindicación. 
5. La creación de partidas presupuestales para las direcciones provinciales y nacionales de educación bilingüe. Entrega de recursos permanentes del convenio MEC-CONAIE.

6. Condonación de las deudas por parte de varios organismos,35 de acuerdo a las exigencias de la CONAIE. Reforma del artículo primero de la Constitución de la República, por el cual nuestro país sea declarado un estado plurinacional.

7. Reforma al artículo 1 de la Constitución de la República, declarando al país un Estado Plurinacional.

8. Entrega inmediata de fondos presupuestarios para las nacionalidades indígenas, a través de un proyecto de ley presentado por la CONAIE.

9. Congelamiento de los precios de los productos industrializados de primera necesidad, mínimo por dos años y fijación de precios justos de los productos campesinos de la economía de subsistencia, a través de la autonomía en el mercadeo.

10. Cumplimiento, terminación y realización de las obras prioritarias de la infraestructura básica de las comunidades indígenas.

11. Libre importación y exportación para los comerciantes y artesanos de la CONAIE.

12. Aprobación de ordenanzas para el control, protección y desarrollo de los sitios arqueológicos por la CONAIE y sus organizaciones filiales.

13. Expulsión del Instituto Lingüístico de Verano.

14. Respeto a los derechos del niño y rechazo a las elecciones a la población infantil ${ }^{36}$.

35 Se refiere a instituciones crediticias como el FODERUMA (Fondo de Desarrollo Rural Marginado), el IERAC (Instituto Ecuatoriano de Reforma Agraria y Colonización), FEPP (Fondo Ecuatoriano Populorum Progressio) y el Banco de Fomento.

36 La protesta exigía que a las elecciones por parte de la población infantil le anteceda toda una política de educación y concientización en la realidad nacional. 
15. Decreto de legalización y financiación de la práctica de la medicina indígena.

16. Derogatoria de los decretos que han creado instituciones paralelas a los consejos provinciales y municipales como el CONOFORT, instituciones dirigidas por un solo partido político, con fines electorales que trafican con la conciencia de nuestras comunidades indígenas ${ }^{37}$.

El "Levantamiento Indígena Nacional" se manifestaba entonces con la consigna Tierra, Cultura y Libertad. La medida implicaba el cierre de vías y la toma de tierras de grandes haciendas, como una medida reivindicatoria por tierras que les pertenecía. Por lo que la movilización del sector indígena no solo incluía demandas por la propiedad comunitaria, sino además por su reconocimiento social, político y cultural, en un contexto nacional e internacional de auge del neoliberalismo.

Este levantamiento, que no solo significó el inicio de todo un ciclo de luchas de los indígenas en la región, tuvo además, en lo que aquí interesa destacar, el logro de visualizar la magnitud y fuerza del movimiento indígena, no solo frente al Estado, sino a la población en general, con lo cual se negaba la idea predominante e impregnada en el imaginario social hasta los ochenta, de que los indios eran una "raza" vencida en vías de extinción ${ }^{38}$.

El indígena que no solo fue históricamente excluido, sino además simbolizado como ignorante y sin cultura, era en este momento

37 CONAIE. "Mandato por la defensa de la vida y los derechos de las nacionalidades indígenas", en El levantamiento indígena y la cuestión nacional, Quito: ILDIS, Editorial Abya-Yala, CDDH, 1996, p. 105.

SILVA, Erika. Identidad Nacional y Poder, Quito: Editorial Abya Yala, 2005, p. 54. 
el nuevo y más importante actor político en el país. La CONAIE, que se constituyó como contraparte al Estado, obtuvo legitimidad y reconocimiento al ser la interlocutora ante el Estado, y con ello, por primera vez en la historia una organización que representa al sector indígena, catalizaba el estado de descontento y de aspiraciones de estos.

Un hecho tan simple como el ingreso de varios indígenas al Palacio de Carondelet significó, que por primera vez un acto de protesta permitiera ingresar en el espacio del otro (...) en el núcleo mismo de la autoridad que se le ha impuesto y la cual de facto le reconocía como colectividad. Que la radio, la prensa y la TV hablen en primer plano de ella, completan el hecho $^{39}$.

No es, por lo tanto, casual que el INEC haya incorporado una pregunta que visualice a un sector que para esa época incursionaba de forma tan marcada en el escenario político. La dificultad se encuentra, al igual que en el censo anterior, en que continúa siendo el Estado quien establece los criterios para identificar lo indígena. Por tanto, aunque signifique un avance la identificación de este sector de la sociedad en las cifras de población, los criterios utilizados aún dan cuenta de sus limitaciones. En cuarenta años, tan solo 14.755 indígenas se sumaban a la cifra del censo de 1950, cuando durante el mismo período, la población nacional pasó de 2`855.012 a 9`285.689 habitantes.

39 LEÓN TRUJILLO, Jorge. “Las organizaciones indígenas: igualdad y diferencia. La afirmación de los conquistados", en AAVV, Indios. Una reflexión sobre el levantamiento indígena de 1990, Quito: Editorial Abya-Yala, 1992, p. 411. 
Es posible encontrar bajo estas cifras que la población indígena identificada en 1990 registra un crecimiento muy bajo respecto de la población nacional. Lo más preocupante se muestra cuando comparamos estas cifras con el censo de 1950. En el primer censo poblacional, el 13,6\% de la población es indígena y para 1990, solo un $3,8 \%$. No sólo que el porcentaje disminuye de manera llamativa (que estadísticamente es posible explicar por el propio crecimiento poblacional), sino que la tasa de crecimiento es muy baja respecto de la tasa de crecimiento nacional del mismo período. Mientras la población ecuatoriana tuvo en cuatro décadas una taza de crecimiento del $22 \%$, la población indígena mostró en el mismo período un crecimiento del 4,2\%. Tan solo 15.000 personas en cuarenta años.

Si se contextualizan las cifras, es posible vincularlas con la década en la que el movimiento indígena experimentó las peores condiciones de exclusión y marginación social. A ello se pueden formular dos tesis. Una primera, que dando la razón a las demandas de inicio de los noventa, pone en evidencia las condiciones de extrema pobreza de la población indígena; y una segunda, que confirma que bajo los criterios estadísticos usados en el censo de 1990, el Estado se rehusaba a reconocer que un importante porcentaje de la población era indígena.

Lo cierto es que reconocer que la población indígena en el Ecuador era representativa significaría legitimar los eventos de junio de 1990 cuando el Paro Nacional Indígena paralizó al país, pero además significaba legitimar y confirmar la principal demanda de los indígenas por la declaración del Estado Plurinacional. De allí que, como plantearemos, la Constituyente de 1998 se verá obligada no solo a desconocer el Estado Plurinacional, sino a reafirmar la idea de un Estado unitario, reduciendo tal demanda 
a lo pluricultural y multiétnico (Art. 1), reconociendo solamente la existencia de pueblos indígenas "que se autodefinen como nacionalidades ancestrales" (Art. 83).

No se puede dejar de mencionar que los noventa son también para el Ecuador la década de mayor crisis política e institucional. Luego del Paro Nacional Indígena de 1990, los indígenas continuaron gestando fuertes movilizaciones nacionales hasta 1996, y en 1997, cuando aparece el brazo político de la CONAIE, el Movimiento de Unidad Plurinacional Pachakutik (MUPP), que, a pesar de las fricciones con el movimiento indígena, presentó a la Constituyente lo que se denominó la "Constitución del Pueblo", con todas las demandas antes mencionadas. Como era de esperar; estas demandas no fueron aceptadas, pero permitió hacerlas públicas.

Las demandas indígenas van a chocar en la Constituyente de 1997 con un constitucionalismo liberal que, por un lado, se apoya en una idea de igualdad formal, que termina negando la amplia diversidad cultural del país, y por otro, en una idea de soberanía que, con base un sistema representativo excluyente, hace del campo político un círculo exclusivo, basado en la "raza", en la clasificación de identidades sociales, en donde el blanco y criollo ocupan un lugar privilegiado, lo que Aníbal Quijano llamaría la "colonialidad del poder" 40 .

Esto que GARGARELLA explica como la tensión entre el constitucionalismo liberal-conservador y una forma de constitucionalismo radical dejó entrever, a nuestro entender,

40 QUIJANO, Aníbal. "Colonialidad y modernidad/racionalidad" en Revista Perú Indígena, Lima: Vol. 13, N.2 29, 1992. 
que las demandas indígenas introdujeron al debate político tesis radicales de contenido anticolonial, que planteaban profundas reformas al sistema político, tanto que su reconocimiento lo colocaría en crisis. Se evidenció que lo indígena suponía para el poder político y económico un grave cuestionamiento a los procesos de desarrollo y modernización en un marco de una teoría liberal. De allí que desde las esferas del poder, se optaba por manejar un discurso de "cultura nacional", sustentada en el mestizaje con la adopción de valores y prácticas de Occidente. El gobierno de Rodrigo Borja, por mencionar un ejemplo, deslegitimaba el discurso indígena, tachándolo de separatista, sectario y contrario a la idea de Estado unitario.

La Constitución de 1998, que se limitó a reconocer el carácter multiétnico y pluricultural del Estado (Art. 1) e incorporó algunos artículos sobre derechos colectivos para los pueblos indígenas (artículos 85 y 86) ${ }^{41}$, también declaraba que: "Los pueblos indígenas, que se autodefinen como nacionalidades de raíces ancestrales (...) forman parte del Estado ecuatoriano único e indivisible". ${ }^{42}$ El poder estatal se resistía, a pesar de las cifras, a reconocer la principal demanda indígena; el reconocimiento del Estado como Plurinacional, apelando a la unidad de éste.

41 Conservar la propiedad imprescriptible de las tierras comunitarias, que serán inalienables, inembargables, e indivisibles, salvo la faculta del Estado para declararlas de utilidad pública. Mantener la posesión ancestral de las tierras comunitarias y a obtener su adjudicación gratuita, conforme a la ley. Ser consultados sobre planes y programas de prospección y explotación de recursos no renovables que se hallen en sus tierras y que puedan afectarlos ambiental y culturalmente; participar en los beneficios que esos proyectos reporten, en cuanto sea posible y recibir indemnizaciones por los perjuicios socio-ambientales que les causen". No ser desplazados, como pueblos, de sus tierras.

Artículo 83, Constitución del Ecuador, R. O. N. ${ }^{\circ}$ 001, de 11 de agosto de 1998. 
Se debe tomar en cuenta que el reconocimiento del Estado como pluricultural y multiétnico es insuficiente ante la Plurinacionalidad, dado que contiene la noción liberal del multiculturalismo, que pone como límites a los derechos de las minorías, los principios de libertad individual, democracia y justicia social. La demanda por un Estado Plurinacional sobrepasa, pero además, cuestiona la teoría liberal del Estado y la democracia. La tesis del multiculturalismo fue vista bajo sospecha y con cierta distancia desde la organización social indígena.

Según Catherine WALSH, el multiculturalismo que se halla detrás de la idea de un Estado multiétnico y pluricultural merece “...verlo como una nueva estrategia de control político de la diferencia, ahora no sólo con intereses nacionales, sino también transnacionales y capitalistas." 43 Para Armando MUYOLEMA, el multiculturalismo "...sustenta la producción y administración de la diferencia dentro del orden nacional, volviéndola funcional a la expansión del neoliberalismo, por un lado y, por otro, contribuyendo eficazmente al desagravio ideológico frente a los indios aunque el orden de dominación no haya sido realmente afectado" 44 .

En definitiva, la Constitución de 1998 significó un avance importante, pero no suficiente para el movimiento indígena; el poder político, sin embargo, no podía por mucho más insistir en el Estado unitario.

43 WALSH, Catherine. "De-colonialidad e interculturalidad: Reflexiones desde proyectos político-epistémicos" en Yapu, Mario. Modernidad y pensamiento descolonizador. La Paz: IFEA-PIEB, 2006, p. 172.

44 MUYOLEMA, Armando, citado por Walsh, C., op cit., p. 172. 
En noviembre de 2001, se lleva a cabo el VI Censo de Población y V de Vivienda, incorporándose por primera vez en la boleta censal la variable de autoidentificación. Junto a la pregunta por el idioma o lengua que se habla (Pregunta 5), se consultó además "Cómo se considera: ¿indígena, negro (Afro-ecuatoriano), mestizo, mulato, blanco u otro?" 45 El censo registró un total de 830.418 personas que se autoidentificaron como indígenas, cifra que representa el $6,8 \%$ de la población nacional, que para aquel momento llegó a 12`156.608 habitantes.

Aunque las opiniones sobre la pregunta en torno a la autoidentificación generó distintas opiniones sobre su conveniencia y efectividad, lo cierto es que la simple incorporación a la boleta censal significaba un avance importante respecto de los procesos censales pasados, pues establecía la posibilidad de que sea el propio individuo quien determine su identidad, lo cual significaba conferirle voz propia al indígena.

Visto así, el período 1991-2001 muestra un escenario totalmente distinto. En diecinueve años se registra un crecimiento que, aunque es reducido frente a la población nacional (3,8\% a 6,8\%), no es menor como tasa de crecimiento (129\%). Una posible explicación a este cambio demográfico -consideramos- responde precisamente -entre otros factores- al proceso de reivindicación de derechos que antecedieron. En este sentido, CHISAGUANO menciona que el crecimiento poblacional puede deberse:

[a que] la población indígena protagonizó una nueva dinámica de convivencia social, tomando con mucha fuerza el proceso de reindianización y revalorización

INEC, Evolución de las variables investigadas..., op cit., anexo. 
cultural, lo indígena no lo toman ya más como un signo de inferioridad, sino que aprovechan de la situación de exclusión y marginación para problematizarla y tomarla como plataforma de lucha reivindicativa, sus propuestas son expuestas públicamente, sea en el país como en el exterior y son parte de las agendas de las organizaciones locales y nacionales ${ }^{46}$.

Es posible afirmar, entonces, que en el ámbito estadístico, el período de caída de la tasa de crecimiento poblacional 1950-1990, cierra con el largo proceso de exclusión, pero principalmente de negación de lo indígena, en tanto que el período 1990-2001, se abre progresivamente como un nuevo y prometedor panorama político, social y económico para el sector indígena, hecho que, como se mencionó, lleva de la mano la ubicación de éste como un actor importante en la política nacional.

Entre 1998 y 2000, el movimiento indígena se articula con otros sectores en descontento con las políticas de ajuste que el gobierno de Jamil Mahuad impulsaba. La CONAIE, que se manifestaba desde Quito en contra de todo el aparato estatal, exigió la salida de los tres poderes y constituyó lo que denominó como "Parlamento Nacional de los Pueblos del Ecuador". En enero de 2000 un grupo de indígenas y militares se tomó el Congreso e integró la "Junta de Salvación Nacional". Mahuad abandonaría el cargo y lo asumiría el vicepresidente, Gustavo Noboa Bejarano. De todo este contexto político, lo que interesa aquí resaltar es el hecho de la diversidad de demandas que se conjugaron en el momento, debido a las distintas alianzas que se gestaron (sindicatos, organizaciones barriales, fuerzas armadas, gremios, partidos políticos, etc). Este

46 CHISAGUANO, op cit., p. 18. 
hecho, según CRUZ RODRÍGUEZ, generó algunas tensiones con las bases indígenas que criticaron el afán de tomar el poder cuando el objetivo era construirlo "desde abajo" 47 .

En una siguiente fase, en la Constituyente de 2008, se genera un nuevo escenario socio-político; la situación del movimiento indígena que tras su alianza con Gutiérrez en 2003 había perdido cierta legitimidad, es distinta al contexto de 1990. Tras la Rebelión de los forajidos en abril de 2005, un nuevo actor ciudadano, de clase media y capitalino es el que empieza a ocupar ese lugar ${ }^{48}$.

Más allá de esto y de cara a la Constituyente de Montecristi, la CONAIE anunció su intención por reintroducir el debate sobre plurinacionalidad, lanzando el documento "Constitución del Estado Plurinacional de la República del Ecuador", y mediante un boletín de prensa, declaraba:

Es el momento preciso e histórico para que los pueblos y nacionalidades indígenas y los sectores sociales del país hagamos un cambio estructural, político y jurídico del Estado ecuatoriano. Desde 1830 hasta la actualidad se ha redactado 19 Constituciones sin la participación plena de los Pueblos y Nacionalidades Indígenas y se ha constituido los poderes del Estado como un resultado del régimen colonial dominante. Tenemos que

CRUZ RODRÍGUEZ, Edwin. "Redefiniendo la nación: Luchas indígenas y Estado Plurinacional en Ecuador (1990-2008)", en Nómadas, Revista Científica de Ciencias Sociales y Jurídicas, Numero Especial, abril 2012. Internet http:/ / revistas.ucm.es/index.php/NOMA/article/view/41786 (visita 25-04-16).

Sobre este hecho ver NAVAS ALVEAR, Marco. Lo público insurgente. Crisis y construcción de la política en la esfera pública. Quito: CIESPAL- Universidad Andina Simón Bolivar, 2012. 
construir un Estado diferente, el Estado plurinacional para erradicar el regionalismo y la excusión que hemos sido sometidos por un Estado impuesto piramidal y su forma de gobierno excluyente, autoritario, represivo. Queremos construir un Estado Plurinacional, pluricultural, de democracia participativa y directa, como un nuevo modelo de organización política para la descolonización de nuestras naciones y pueblos, y para hacer realidad del principio de un país con unidad en diversidad e igualdad social ${ }^{49}$.

En 2008, la Constituyente reconoce el Estado Plurinacional, no obstante, y es aquí en donde proponemos tomar atención, su reconocimiento parece no responder a la misma lucha que presidió en las Constituyentes de 1978 y 1998. En Montecristi, el discurso sobre plurinacionalidad es apropiado por el oficialismo, y aunque no dejó de generar resistencia en los debates constituyentes, su actual reconocimiento continúa entrando en tensión con un modelo liberal aún presente en la Constitución de 2008. No se puede desmerecer, sin embargo, que tanto la declaración del Estado Plurinacional, los principios del Sumak Kawsay, el reconocimiento de los Derechos de la Naturaleza, la invocación de la Pacha Mama en el Preámbulo, y varios otros derechos dirigidos a los pueblos y nacionalidades indígenas son nuevamente un efecto del proceso de lucha entre el poder y el sector indígena por su reconocimiento.

49 "Resolución de la CONAIE, 22 de octubre de 2007", en CONAIE, Propuesta de la CONAIE frente a la Asamblea Constituyente. Principios y lineamientos para la nueva constitución del Ecuador. Por un Estado Plurinacional, Unitario, Soberano, Incluyente, Equitativo y Laico, en internet. https://www.yachana.org/ earchivo/conaie/ConaiePropuestaAsamblea.pdf (visita 20-04-16). 


\section{BIBLIOGRAFÍA.}

AAVV, El levantamiento indígena y la cuestión nacional. Quito: ILDIS, Editorial Abya-Yala, CDDH, 1996.

, Indios. Una reflexión sobre el levantamiento indígena de 1990, Quito, Editorial Abya-Yala, 1992.

CEPAL, Población indígena y afroecuatoriana en Ecuador: Diagnóstico sociodemográfico a partir del censo de 2001. Santiago de Chile, 2005.

Chisaguano, Silverio. La Población Indígena del Ecuador. Análisis e Estadísticas socio-demográficas. Quito: INEC, 2006.

CRUZ Rodríguez, Edwin. "Redefiniendo la nación: Luchas indígenas y Estado Plurinacional en Ecuador (19902008)", en Nómadas, Revista científica de ciencias sociales y jurídicas, Numero especial, abril, 2012.

DÁVAlos, Pablo. El movimiento indígena ecuatoriano: la constitución de un actor político.

FOUCAUlT, Michael. Seguridad, Territorio y Población, Trad. de Horacio Pons. Buenos Aires: Fondo de Cultura Económica, 2006.

, Defender la sociedad. Buenos Aires: Fondo de Cultura Económica, 2008. 
GARGARELLA, Roberto. La sala de máquinas de la Constitución. Dos siglos de constitucionalismo en América Latina (1810-2010). Buenos Aires: Katz, 2015.

Hurtado, Osvaldo. Política Democrática: los últimos veinte y cinco años, Quito: FESO, Corporación Editora Nacional, 1990.

INEC, Evolución de las variables investigadas en los censos de población y vivienda del Ecuador. 1950, 1962, 1974, 1982, 1990, 2001 y 2010, Anexo.

KNAPP, Gregory. Geografía Quichua de la Sierra del Ecuador. Núcleos, dominios y esfera, Quito: Editorial Abya-Yala, 1987.

MALDONADO, Luis. "Movimiento indígena y participación política en Ecuador", en Incidencia de la participación política de los pueblos indígenas: un intercambio de experiencia de Bolivia, Ecuadory Guatemala. Guatemala: Fundación Konrad Adenauer, 2006.

Ministerio de ECONOMÍA, Primer Censo de Población del Ecuador, 1950, Resumen de Características, Volumen único, Quito: Ministerio de Economía, 1960.

NAVAS ALVEAR, Marco. Lo público insurgente. Crisis y construcción de la política en la esfera pública, Quito, CIESPAL- Universidad Andina Simón Bolivar, 2012.

PRIETO, Mercedes. "El estado ecuatoriano a mediados del siglo $\mathrm{XX}$ : el censo, la población y la familia indígena", en 
Revista Europea de Estudios Latinoamericanos y del Caribe (ERLACS), N. ${ }^{\circ}$ 99, octubre, 2015.

QUIJAJO, Aníbal. "Colonialidad y modernidad/racionalidad”, en Revista Perú Indígena, Lima: Volumen 13, N. 29, 1992.

SÁnCHEZ-PARGA, José. Población y pobreza indígenas, Quito: CAAP, 1996.

SILVA, Erika. Identidad Nacional y Poder, Quito: Editorial Abya Yala, 2005.

YAPU, Mario. Modernidad y pensamiento descolonizador. La Paz: IFEA-PIEB, 2006. 